\title{
Seroprevalence of anti-Toxoplasma gondii antibodies in Egyptian sheep and goats
}

\author{
Yara M. Al-Kappany ${ }^{1 \dagger}$, Ibrahim E. Abbas ${ }^{1 \dagger}$, Brecht Devleesschauwer ${ }^{2^{*}}$ (D), Pierre Dorny ${ }^{3,4}$, Malgorzata Jennes ${ }^{5 \dagger}$ \\ and Eric Cox ${ }^{5+}$
}

\begin{abstract}
Background: Toxoplasmosis is a zoonotic disease that affects a wide range of animals, including small ruminants. Sheep and goats are considered as biological indicators for the contamination of the environment with Toxoplasma gondii oocysts. In addition, in countries such as Egypt, where sheep and goat meat is frequently consumed, $T$. gondii infection in small ruminants may also pose a public health risk. To establish baseline estimates of the prevalence of T. gondii infection in Egyptian small ruminants, we used an indirect immunofluorescence assay (IFA) and an enzyme-linked immunosorbent assay (ELISA) to assess the seroprevalence in 398 sheep from four Egyptian governorates (Cairo, Giza, Dakahlia and Sharkia) and in 100 goats from Dakahlia. The positive and negative agreements of both tests were calculated and the true prevalence was estimated using a Bayesian approach.

Results: The true prevalence of antibodies to T. gondii as determined by both tests was higher in Egyptian goats (62\%) than in sheep for each province (between 4.1 and 26\%). Sheep slaughtered at the Cairo abattoir had the lowest true prevalence (4.1\%), while true prevalences in Dakahlia, Giza and Sharkia governorates (26\%, 23\% and $12 \%$, respectively) were substantially higher.
\end{abstract}

Conclusions: The high prevalence of antibodies to T. gondii may indicate an important role of goat and sheep in the transmission of human toxoplasmosis in Egypt, given the habit of eating undercooked grilled mutton.

Keywords: Egypt, Filter paper, Small ruminants, Toxoplasma gondii, True prevalence

\section{Background}

Toxoplasmosis is a globally distributed zoonotic disease with important medical and economic implications for man and animals, respectively [1]. Infection of sheep and goats with Toxoplasma gondii may cause abortion, stillbirth and neonatal death [2]. T. gondii infection in small ruminants also poses a public health risk, since man can acquire $T$. gondii from infected sheep and goats through consumption of undercooked meat, drinking unpasteurized milk or handling raw meat [3].

Many studies have assessed the seroprevalence of $T$. gondii in sheep and goats in different parts of the world using different serological techniques [1]. In Egypt, around 10 million small ruminants are yearly produced with slightly more than $50 \%$ kept in small herds with less

\footnotetext{
* Correspondence: brechtdv@gmail.com; brecht.devleesschauwer@wiv-isp.be ${ }^{\dagger}$ Equal contributors

${ }^{2}$ Department of Public Health and Surveillance, Scientific Institute of Public Health (WIV-ISP), Rue Juliette Wytsmanstraat 14, 1050 Brussels, Belgium Full list of author information is available at the end of the article
}

than 10 animals, and $25 \%$ owned by people without agricultural land. The prevalence of $T$. gondii infection in sheep in Egypt has been shown to range between 34 and $100 \%[4,5]$, and that in goats between 42 and $60 \%[5,6]$. However, these studies were limited to one of the Egyptian governorates (respectively, Cairo [4], Faiyum [5], and Giza [6]). Moreover, no previous report investigated the prevalence of $T$. gondii infection in the Dakahlia governorate, one of the Nile delta governorates (Fig. 1).

We aimed to assess the prevalence of anti- $T$. gondii antibodies in sera of Egyptian goats in the Dakahlia governorate and sheep in four Egyptian governorates (Cairo, Dakahlia, Giza and Sharkia).

\section{Methods \\ Sample collection}

Blood samples were obtained from 100 goats (reared at villagers' houses at Dakahlia governorate) and 398 sheep slaughtered at the main abattoir in four Egyptian governorates: Cairo (urban) $(n=100)$, Dakahlia $(n=100)$ and 


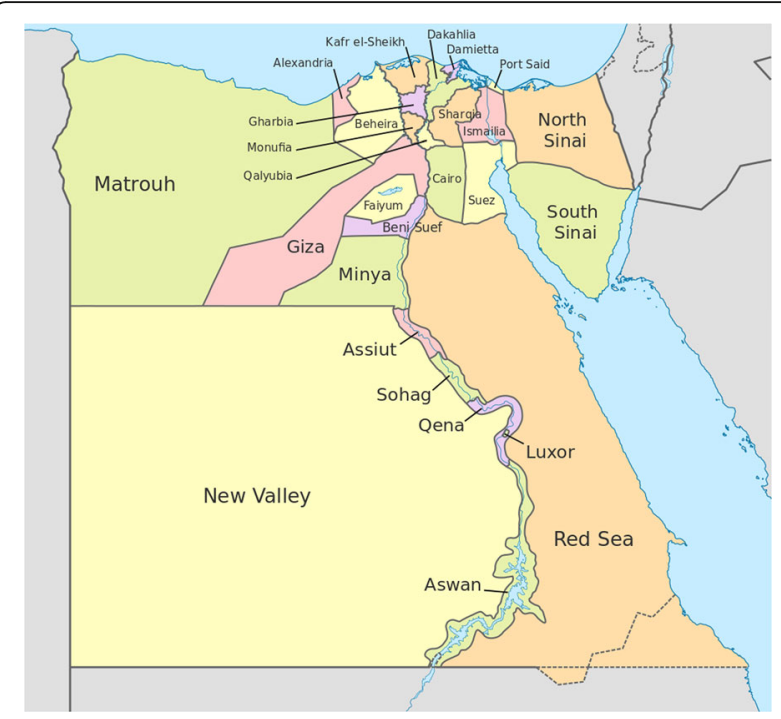

Fig. 1 Governorates of Egypt. CC BY-SA

3.0, https://commons.wikimedia.org/w/index.php?curid=32089528

Sharkia $(n=99)$ in the Nile delta and Giza $(n=99)$ (middle Egypt). The Cairo governorate is the most populated of the governorates and completely urbanized. Dakahlia and Sharkia governorates are both located in the Nile Delta, a highly populated agricultural region. The Giza governorate is one of the largest agricultural governorates in Egypt and represents middle Egypt. Sera were collected and stored at $-20{ }^{\circ} \mathrm{C}$ until preparation for transport to Belgium and further analysis. Long-term storage of serum normally needs refrigeration or freezing; furthermore, transport of sera from countries with transboundary animal diseases to other countries free of these diseases is not allowed. Therefore, sera were first filtered over a $0.2 \mu \mathrm{m}$ filter (Pall Life Sciences, USA), thereby removing possible bacterial contaminants [7]. Then, $5 \mu \mathrm{l}$ from each sample was spotted on Whatman filter paper No 4 (Whatman international Ltd., Maidstone, England), whereafter this paper was heat-treated in a household oven at $60{ }^{\circ} \mathrm{C}$ for $180 \mathrm{~min}$ to inactivate possible viral contaminants such as foot-and-mouth disease virus and Rift Valley fever virus [8,9]. An import permit was obtained from the Federal Agency for the Safety of the Food Chain, Belgium (1069371) and the dried filter papers were transported in sealed bags to the Laboratory of Immunology, Faculty of Veterinary Medicine, Ghent University, Belgium. There, each serum spot was cut out the filter paper and dialyzed against $500 \mu \mathrm{l}$ of phosphate buffered saline (PBS) supplemented with 0 . $2 \%$ Tween $^{\circ} 20$ (PBS-Tw). Finally, this 1:100 serum dilution in PBS-Tw was used for antibody testing by an indirect immunofluorescence assay (IFA) and an enzyme-linked immunosorbent assay (ELISA).

\section{Indirect immunofluorescence assay}

Formalin-treated tachyzoites of an RH T. gondii strain coated on IFA slides (Toxo-Spot ${ }^{\ominus}$ IF, Bio-Mérieux, France) were incubated for $30 \mathrm{~min}$ at $37^{\circ} \mathrm{C}$ with $50 \mu \mathrm{l}$ of $1 / 100$ in PBS diluted serum samples. After washing with PBS, the slides were incubated for $30 \mathrm{~min}$ at $37{ }^{\circ} \mathrm{C}$ with $30 \mu \mathrm{l}$ of fluorescein isothiocyanate conjugated rabbitanti-sheep IgG or rabbit-anti-goat IgG (Bethyl Laboratories. Inc., Montgomery USA), diluted in PBS-Evans Blue (counter dye). After washing and drying, the slides were interpreted using a fluorescence microscope. The cut-off read-out of the fluorescence test was established at a dilution of 1/50 with Toxoplasma negative and positive sheep reference sera (collected during the 2011 Maedi-Visna screening and validated with the MAT assay), according to the Toxo-Spot ${ }^{\circ}$ IF guidelines.

\section{Enzyme-linked immunosorbent assay}

All collected sera were tested for the presence of IgG antibodies against Toxoplasma total lysate antigen (TLA) according to the ELISA described by Verhelst et al. [10]. Absorbance was read at $405 \mathrm{~nm}$ using an iMARK Microplate reader (Biorad, Nazareth, Belgium). The cut-off value, calculated as the mean optical density plus three times the standard deviation of three negative sheep and goat sera (collected during the 2011 MaediVisna screening and validated with the MAT assay) assayed at a 1/100 dilution, was 0.395 for sheep and 0 . 159 for goat.

\section{Data analysis}

Based on the observed test results, we calculated prevalences and corresponding 95\% exact confidence intervals (CI) using the prevalence package for $\mathrm{R} 3.4 .0[11,12]$. Agreement between the results of both serological tests was quantified as the positive agreement index, $P A=2 a$ / $(2 a+b+c)$, and the negative agreement index, $N A=2 d /$ $(2 d+b+c)$, with $\{a, b, c, d\}$ the cell values of the concerned two-by-two table [13]. Confidence intervals for $P A$ and $N A$ were obtained through bootstrapping using 1,000,000 Dirichlet random deviates, implemented via the mc2d package for R 3.4 .0 [12, 14].

As serological assays may yield false positive or false negative results, the observed test results only represent an apparent prevalence estimate [15]. To account for the imperfectness of the serological assays and the lack of a gold standard assay, we estimated true prevalence in a Bayesian framework, taking into account external information on diagnostic sensitivity and specificity of both assays. We assumed a Beta $(1,1)$ prior for the true prevalence, and derived prior Beta distributions for the sensitivity and specificity of the IFA and ELISA from Shaapan et al. [4] (Table 1). A Uniform $(-0.25,0.25)$ prior was used for the covariance between both tests. 
Table 1 Prior information on diagnostic sensitivity and specificity of the applied assays, based on Shaapan et al. [4]

\begin{tabular}{|c|c|c|c|c|c|c|}
\hline \multirow[t]{2}{*}{ Test } & \multicolumn{3}{|l|}{ Sensitivity } & \multicolumn{3}{|l|}{ Specificity } \\
\hline & Distribution & Mean & $95 \%$ UI & Distribution & Mean & $95 \%$ UI \\
\hline IFA & $\operatorname{Beta}(82,20)$ & 0.80 & $(0.72-0.87)$ & $\operatorname{Beta}(181,17)$ & 0.91 & $(0.87-0.95)$ \\
\hline ELISA & $\operatorname{Beta}(92,10)$ & 0.90 & $(0.84-0.95)$ & Beta $(170,28)$ & 0.86 & $(0.81-0.90)$ \\
\hline
\end{tabular}

UI uncertainty interval, IFA indirect immunofluorescence assay, ELISA enzymelinked immunosorbent assay

Models were implemented independently for the five datasets. For each model, we simulated two chains of 20,000 iterations, of which the first 10,000 were discarded as burn-in. Convergence of the models was visually assessed using trace and density plots and numerically using the multivariate potential scale reduction factor [16]. The models were implemented in R 3.4. 0 [12] using the prevalence package version 0.4.0 [11].

\section{Results}

Apparent prevalence and between-test agreement Table 2 shows the apparent test results per population and per diagnostic test, while Table 3 shows the crossclassification of samples based on both diagnostic tests. Across sheep sera, a positive agreement of $0.78(95 \% \mathrm{CI}$ $0.71-0.83)$ and a negative agreement of $0.92(0.90-0.94)$ was found. Across goat sera, a positive agreement of 0 . 94 (95\% CI $0.88-0.97)$ and a negative agreement of 0.92 (0.85-0.97) was found.

\section{True prevalence of anti-toxoplasma gondii antibodies in sheep and goats}

The true prevalence of anti- $T$. gondii antibodies in the sera from the Egyptian goats was 62\% (95\% uncertainty interval [UI] 52-73\%). The true prevalence in sheep varied between $4.1 \%$ and $26 \%$ in the four governorates. Specifically, Cairo had the lowest true prevalence $(4.1 \%$; 95\%UI $0.2-11 \%$ ), while higher and more similar prevalences were noted in Dakahlia (26\%; 95\%UI 16-36\%) and Giza (23\%; 95\%UI 14-33\%). An intermediate value was found for Sharkia governorate (12\%; 95\%UI 3.0$21 \%)$.

\section{Discussion}

T. gondii is widely prevalent in Egyptian sheep and goats, which may indicate an important role of small ruminants in the transmission of human toxoplasmosis in Egypt, especially when considering the Egyptian people's habit of eating undercooked grilled mutton and goat meat (Kabab and Kofta) [17]. The true prevalence was approximately two-fold higher in goats than in sheep in Dakahlia. The higher prevalence in goats was in line with Barakat et al. [6], who found prevalences of $55 \%$ and $44 \%$ in 306 goats and 320 sheep, respectively, from the Giza governorate; however, Ghoneim et al. [5] found prevalences of $42 \%$ and near $100 \%$ in 10 goats and 61 sheep from the Faiyum governorate, but this could have been due to the very low sample size. A higher $T$. gondii infection in goats than in sheep may be due to differences in herding practices [18], although this requires further investigation. The observed difference may also be confounded by a different age at slaughter; unfortunately, information on the age of the sampled animals was not available. Nonetheless, this high prevalence underlines the need to give extra attention to goats as a source for infection of humans, which is estimated to be 51\% among pregnant women in Egypt [19]. Indeed, in most of the Egyptian rural areas, goat meat and milk are important human food products, which could facilitate the spread of toxoplasmosis to humans.

Our sheep study was carried out over four Egyptian Provinces: Cairo, Sharkia, Dakahlia, and Giza. The latter two governorates showed a nearly similar true prevalence (26\%, and $23 \%$, respectively), while an intermediate $(12 \%)$ and very low value $(4.1 \%)$ was found for Sharkia and Cairo, respectively. This may be attributed to the fact that Cairo (Capital of Egypt) is an urban area, with a lower cat density, unlike the three other rural governorates where cats are kept by the villagers as natural predators. Previous studies found $44 \%$ positive sheep sera in the Giza governorate [6], versus $46 \%$ and $42 \%$ in the Cairo governorate $[4,20]$; thus not suggesting a lower prevalence in the urbanized Cairo governorate than in the rural governorates. However, no comparison with the other rural governorates was performed within the same study. More extensive sampling of sheep over time in different slaughterhouses in Cairo and in parallel in one of the three rural governorates will be needed to confirm our observation.

Our prevalences in sheep were lower than in other studies. This could be due to the specific pre-treatment

Table 2 Positive samples $(x)$ and apparent prevalence (AP, \%) with 95\% exact confidence interval (CI) for Toxoplasma gondii infection by population and diagnostic test

\begin{tabular}{|c|c|c|c|c|c|c|c|c|c|c|}
\hline \multirow{2}{*}{$\begin{array}{l}\text { Diagnostic } \\
\text { test }\end{array}$} & \multicolumn{2}{|c|}{ Goats, Dakahlia $(n=100)$} & \multicolumn{2}{|c|}{ Sheep, Cairo $(n=100)$} & \multicolumn{2}{|c|}{ Sheep, Dakahlia $(n=100)$} & \multicolumn{2}{|c|}{ Sheep, Giza $(n=99)$} & \multicolumn{2}{|c|}{ Sheep, Sharkia $(n=99)$} \\
\hline & $x$ & AP $(95 \% \mathrm{Cl})$ & $x$ & AP $(95 \% C l)$ & $x$ & AP $(95 \% \mathrm{Cl})$ & $x$ & AP $(95 \% \mathrm{Cl})$ & $x$ & AP $(95 \% \mathrm{Cl})$ \\
\hline IFA & 54 & $54(44-64)$ & 20 & $20(13-29)$ & 38 & $38(28-48)$ & 32 & $32(23-42)$ & 34 & $34(25-45)$ \\
\hline ELISA & 59 & $59(49-69)$ & 12 & $12(6.4-20)$ & 27 & $27(19-37)$ & 26 & $26(18-36)$ & 17 & $17(10-26)$ \\
\hline
\end{tabular}

IFA indirect immunofluorescence assay, ELISA enzyme-linked immunosorbent assay 
Table 3 Classification of samples according to indirect immunofluorescence assay (IFA) and enzyme-linked immunosorbent assay (ELISA)

\begin{tabular}{|c|c|c|c|c|c|c|}
\hline \multicolumn{2}{|c|}{ Diagnostic test } & \multirow{2}{*}{$\begin{array}{l}\text { Goats, } \\
\text { Dakahlia }\end{array}$} & \multirow{2}{*}{$\begin{array}{l}\text { Sheep, } \\
\text { Cairo }\end{array}$} & \multirow{2}{*}{$\begin{array}{l}\text { Sheep, } \\
\text { Dakahlia }\end{array}$} & \multirow{2}{*}{$\begin{array}{l}\text { Sheep, } \\
\text { Giza }\end{array}$} & \multirow{2}{*}{$\begin{array}{l}\text { Sheep, } \\
\text { Sharkia }\end{array}$} \\
\hline IFA & ELISA & & & & & \\
\hline 1 & 1 & 80 & 12 & 27 & 24 & 17 \\
\hline 1 & 0 & 44 & 8 & 11 & 8 & 17 \\
\hline 0 & 1 & 2 & 0 & 0 & 2 & 0 \\
\hline 0 & 0 & 272 & 80 & 62 & 65 & 65 \\
\hline
\end{tabular}

$1=$ positive; $0=$ negative

of the serum samples. Nonetheless, previous studies demonstrated a close relation between results of serological tests on blood and serum in comparison with serum elutes from filter paper [8, 21, 22]; furthermore, we clearly showed that the sample treatment still allowed demonstrating $T$. gondii-specific antibodies. However, filter paper elutes have not been used before for demonstrating antibodies against $T$. gondii in sheep and goats. Whether the treatment decreases antibody concentrations and consequently also sensitivity should therefore be assessed. Nonetheless, since all samples were treated in a similar way in the present study, comparison between samples of different governorates remained possible.

A problem of comparing different seroprevalence studies on $T$. gondii infection remains the wide range of serological assays used [23-25]. In humans the SabinFeldman test is considered the gold standard, but is expensive and holds risks for the user because of the use of live tachyzoites [26]; the test is therefore rarely used in sheep [27]. More often, IFA, ELISA, an indirect hemagglutination assay or a modified agglutination test have been used [25]. IFA and ELISA are fast techniques with high sensitivity and specificity, suitable for epidemiological studies [26]. Previous studies applying the TLA-ELISA on sheep serum samples in the Netherlands [28] and in Cairo Egypt [4] reported sensitivities of 97. $8 \%$ and $90.1 \%$, respectively, and specificities of $96.4 \%$ and $85.9 \%$, respectively. Furthermore, Verhelst et al. [25] found a $100 \%$ agreement between the Toxo-spot IF ${ }^{ø}$ and the TLA-ELISA when applied to Belgian sheep sera. This was not the case in the present study, in which the positive agreement was $78 \%$ and $94 \%$ for sheep and goat sera, respectively, and the negative agreement was $92 \%$ for both sheep and goat sera. Several factors could be responsible for this difference, such as the sampled sheep breeds, the $T$. gondii strains infecting sheep in the field, or the presence of cross-reacting protozoa.

Even though the TLA-ELISA and IFA have been used in several studies, they have not been truly validated for use in sheep and goats. Therefore, in most studies several serological assays were performed and results combined using Bayesian modeling $[25,28]$. Nonetheless, there is a high need for validation and standardization of serological assays for seroprevalence studies on $T$. gondii in different species throughout the world. The accurate measurement of the seroprevalence in a comparative way would be an invaluable help to identify risk factors for infections in different regions and at a flock level. Furthermore, it is important to note that serological responses are only indicative of exposure to parasite antigens, but are not a definitive indication that the animals that tested positive are actually infected and capable of transmitting the infection to humans. For any definitive statement on the human health risk to be made samples of meat or milk would need to be tested by mouse bioassay to prove infectivity.

\section{Conclusion}

For the first time, we compared the prevalence of $T$. gondii infection in sheep across different Egyptian governorates, and demonstrated the prevalence of $T$. gondii infection in small ruminants from the Dakahlia governorate, one of the Nile delta governorates. The high prevalence of antibodies to $T$. gondii may indicate an important role of sheep and goat in the transmission of human toxoplasmosis in Egypt. Further validation of serological assays and methods, as well as molecular characterization studies, may provide further evidence on the public health risk of small ruminant toxoplasmosis in Egypt.

\section{Abbreviations}

AP: Apparent prevalence; Cl: Confidence interval; ELISA: Enzyme-linked immunosorbent assay; IFA: Indirect immunofluorescence assay; NA: Negative agreement index; PA: Positive agreement index; PBS: Phosphate buffered saline; PBS-Tw: Phosphate buffered saline supplemented with 0.2\% Tween ${ }^{\circledast 20 ;}$ TLA: Total lysate antigen; UI: Uncertainty interval

\section{Acknowledgements}

Not applicable.

\section{Funding}

Yara Al-Kappany is the recipient of a scholarship from Erasmus Mundus Action 2 Welcome project funded by the European commission. The funding body had no role in the design of the study and collection, analysis, and interpretation of data and in writing the manuscript.

\section{Availability of data and materials}

The datasets used and analyzed during the current study are available from the corresponding author on reasonable request.

\section{Authors' contributions}

IEA, PD, EC conceived and designed the study. YMA, IEA collected the samples. MJ performed the laboratory analyses. BD analyzed the data. All authors critically appraised and interpreted the results. IEA drafted the first version of the manuscript. All authors provided feedback on the manuscript, and read and approved the final version.

\section{Ethics approval}

Ethical approval was not applicable as no live animals were used in this experiment. Verbal consent was obtained from the sheep and goat owners as most of them are villagers unable to write or read English. 


\section{Consent for publication}

Not applicable.

\section{Competing interests}

$\mathrm{BD}$ is a member of the editorial board (Associate Editor) of BMC Veterinary Research. All other authors declare that they have no competing interests.

\section{Publisher's Note}

Springer Nature remains neutral with regard to jurisdictional claims in published maps and institutional affiliations.

\section{Author details}

'Parasitology Department, Faculty of Veterinary Medicine, Mansoura University, Mansoura, Egypt. ${ }^{2}$ Department of Public Health and Surveillance, Scientific Institute of Public Health (WIV-ISP), Rue Juliette Wytsmanstraat 14, 1050 Brussels, Belgium. ${ }^{3}$ Laboratory of Parasitology, Faculty of Veterinary Medicine, Ghent University, Merelbeke, Belgium. ${ }^{4}$ Department of Biomedical Sciences, Institute of Tropical Medicine, Antwerp, Belgium. ${ }^{5}$ Laboratory of Immunology, Faculty of Veterinary Medicine, Ghent University, Merelbeke, Belgium.

Received: 3 January 2018 Accepted: 21 March 2018 Published online: 02 April 2018

\section{References}

1. Dubey JP. Toxoplasmosis in sheep — the last 20 years. Vet Parasitol. 2009a;163:1-4.

2. Buxton D, Maley SW, Wright SE, Rodger S, Bartley P, Innes EA. Toxoplasma gondii and ovine toxoplasmosis: new aspects of an old story. Vet Parasitol. 2007;149:25-8

3. Boyer KM, Holfels E, Roizen N, Swisher C, Mack D, Remington J, et al. Risk factors for Toxoplasma gondii infection in mothers of infants with congenital toxoplasmosis: implications for prenatal management and screening. Am J Obstet Gynecol. 2005;192:564-71.

4. Shaapan RM, El-Nawawi FA, Tawfik MA. Sensitivity and specificity of various serological tests for the detection of Toxoplasma gondii infection in naturally infected sheep. Vet Parasitol. 2008:153:359-62.

5. Ghoneim NH, Shalaby SI, Hassanain NA, Zeedan GSG, Soliman YA, Abdalhamed AM. Comparative study between serological and molecular methods for diagnosis of toxoplasmosis in women and small ruminants in Egypt. Foodborne Pathog Dis. 2010;7:17-22.

6. Barakat AMA, Elaziz MMA, Fadaly HA. Comparative diagnosis of toxoplasmosis in Egyptian small ruminants by indirect hemagglutination assay and Elisa. Global. Veterinaria. 2009:3:9-14

7. Devleesschauwer B, Pruvot M, Joshi DD, De Craeye S, Jennes M, Ale A, et al. Seroprevalence of zoonotic parasites in pigs slaughtered in the Kathmandu Valley of Nepal. Vector Borne Zoonotic Dis. 2013;13:872-6.

8. Turner C, Williams SM, Cumby TR. The inactivation of foot and mouth disease, Aujeszky's disease and classical swine fever viruses in pig slurry. J Appl Microbiol. 2000:89:760-7.

9. Bellini S, Rutili D, Guberti V. Preventive measures aimed at minimizing the risk of African swine fever virus spread in pig farming systems. Acta Vet Scand. 2016:58:82

10. Verhelst D, De Craeye S, Dorny P, Melkebeek V, Goddeeris B, Cox E, et al IFN- $y$ expression and infectivity of Toxoplasma infected tissues are associated with an antibody response against GRA7 in experimentally infected pigs. Vet Parasitol. 2011;179:14-21.

11. Devleesschauwer B, Torgerson P, Charlier J, Levecke B, Praet N, Roelandt S, et al. Prevalence: tools for prevalence assessment studies. $R$ package version 0.4.0. 2015. http://cran.r-project.org/package=prevalence

12. R Core Team. R: A language and environment for statistical computing. Vienna, Austria: R Foundation for Statistical Computing; 2017. http://www.Rproject.org/.

13. Graham P, Bull B. Approximate standard errors and confidence intervals for indices of positive and negative agreement. J Clin Epidemiol. 1998;51:763-71.

14. Pouillot R, Delignette-Muller M-L. Evaluating variability and uncertainty in microbial quantitative risk assessment using two R packages. Int J Food Microbiol. 2010;142:330-40.

15. Speybroeck N, Devleesschauwer B, Joseph L, Berkvens D. Misclassification errors in prevalence estimation: Bayesian handling with care. Int J Public Health. 2013;58(5):791
16. Brooks SP, Gelman A. General methods for monitoring convergence of iterative simulations. J Comput Graph Stat. 1998:7:434-55.

17. Hassan-Wassef $\mathrm{H}$. Food habits of the Egyptians: newly emerging trends. East Mediterr Health J. 2004;10:898-915.

18. Tegegne D, Abdurahaman M, Yohannes M. Seroepidemiology and associated risk factors of Toxoplasma gondii in sheep and goats in southwestern Ethiopia. BMC Vet Res. 2016;12:280.

19. Ibrahim HM, Huang P, Salem TA, Talaat RM, Nasr MI, Xuan X, et al. Short report: prevalence of Neospora caninum and Toxoplasma gondii antibodies in Northern Egypt. Am J Trop Med Hyg. 2009;80:263-7.

20. El-Ghaysh AA, Mansour MM. Detection of antibodies to Toxoplasma gondi in an Egyptian sheep-herd using modern serological techniques. J Egypt Assoc Immunol. 1994;1:117-21.

21. Uggla A, Nilsson LA. Evaluation of a solid-phase immunoassay (DIG-ELISA) for the serodiagnosis of ovine toxoplasmosis. Vet Immunol Immunopathol. 1987;14:309-18

22. Patel B, Holliman RE. Antibodies to Toxoplasma gondii in eluates from filter paper blood specimens. Br J Biomed Sci. 1994;51:104-8.

23. Dubey JP. Toxoplasmosis of animals and man. 2nd ed. Boca Raton, FL: CRC Press; 2009b.

24. Sakata FB, Bellato V, Sartor AA, de Moura AB, de Souza AP, Farias JA. Toxoplasma gondii antibodies sheep in Lages, Santa Catarina, Brazil, and comparison using IFA and ELISA. Rev Bras Parasitol Vet. 2012;21:196-200.

25. Verhelst D, De Craeye S, Vanrobaeys M, Czaplicki G, Dorny P, Cox E. Seroprevalence of Toxoplasma gondii in domestic sheep in Belgium. Vet Parasitol. 2014;205:57-61.

26. Su C, Dubey JP. Toxoplasma gondii. In: Liu D, editor. Molecular detection of foodborne pathogens. Boca Raton, FL: CRC Press; 2010. p. 741-51.

27. Cicek H, Babur C, Eser M. Seroprevalence of Toxoplasma gondii in Pirlak sheep in the Afyonkarahisar Province of Turkey. Turkiye Parazitol Derg. 2011;35:137-9.

28. Opsteegh M, Teunis $P$, Mensink M, Zuchner L, Titilincu A, Langelaar M, et al. Evaluation of ELISA test characteristics and estimation of Toxoplasma gondii seroprevalence in Dutch sheep using mixture models. Prev Vet Med. 2010;96:232-40.

\section{Submit your next manuscript to BioMed Central and we will help you at every step:}

- We accept pre-submission inquiries

- Our selector tool helps you to find the most relevant journal

- We provide round the clock customer support

- Convenient online submission

- Thorough peer review

- Inclusion in PubMed and all major indexing services

- Maximum visibility for your research

Submit your manuscript at www.biomedcentral.com/submit
Biomed Central 